\title{
Man sollte etwas gegen das Grinsen der deutschen Touristen tun!
}

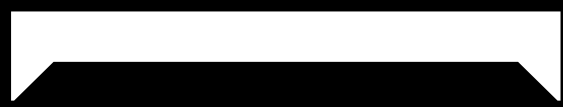

Aberheuteklingt dasWort "Deutsch» nichtmehr so merkwürdio wie damals, als diese noch zu den schwierigen und exotischen Sprachen gehörte, wie Japanisch oder Swahilisch.

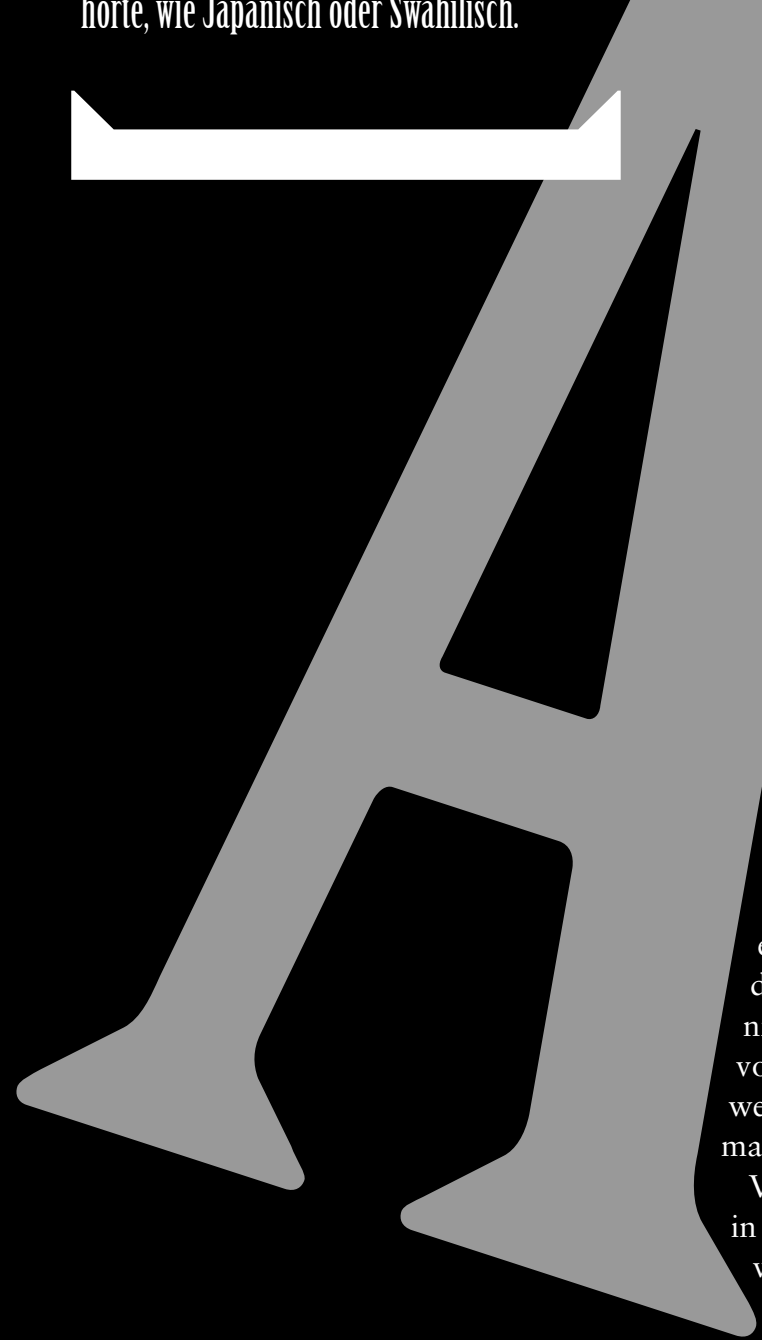

Málaga 
Und es fällt immer wieder ins Auge, wie rücksichtslos die spanischen Unternehmer mit der Sprache Goethes umgehen. Man könnte hier von einem echten Massaker der deutschen Sprache sprechen. Ich persönlich habe das Gefühl, dass, wenn schon mal was richtig geschrieben wird, dies eher dem Zufall als der Absicht zu verdanken ist.

Von Unternehmen, die sonst viel Geld in Design und Werbekampagnen investieren, ließe sich schon etwas mehr Sorgfalt mit dem Umgang des Deutschen erwarten. Diese können es sich schon leisten, die in deutscher Sprache verfassten Texte von einem professionellen Übersetzer revidieren zu lassen, bevor die Produkte an den Konsumenten gelangen und somit auch auf das Image ihrer Produkte ein bisschen mehr Acht geben. Behüte uns Gott!, wenn diese Unternehmen sich bei der Herstellung ihrer Produkte die gleiche Mühe geben und dasselbe Interesse zeigen wie bei der Verfassung deutscher Texte.

Die Beispiele, die ich hier anführe, sind nicht etwa das Ergebnis einer ausführlichen Studie, auch nicht ihrer Krassheit oder Beispielhaftigkeit wegen auserwählte Fälle, sondern ganz einfach Beispiele, die einem Tag für Tag zufällig in die Hände fallen können und die einem Germanisten in den Augen und vor allem im Herz schmerzen.

So findet man bei Mineralwasser-Marken wie Fonter, Sousas oder Fuente Primavera Sachen wie:

NATÜRLICHES MINERALWASSER MIT KOHLENSAÜRE

\section{GERINGEM MINERALGEHALT}

Vor sonnenlicht und geruchseinwirkung schützen - Mindestens haltbar bis ende

\section{Mineral Wasser mit Koblensäure;}

bei Konserven-Unternehmen wie Ramón Peña, Luou Terra, oder Albo Perlen wie:

KLEINEN SARDINEN IN OLIVENÖL Zutaten: Kleinen Sardinen, Olivenöl und salz

\section{EIS VON SEEIGEL}

ZUTATEN: Eis von seeigel, Kochsalz und Walsser

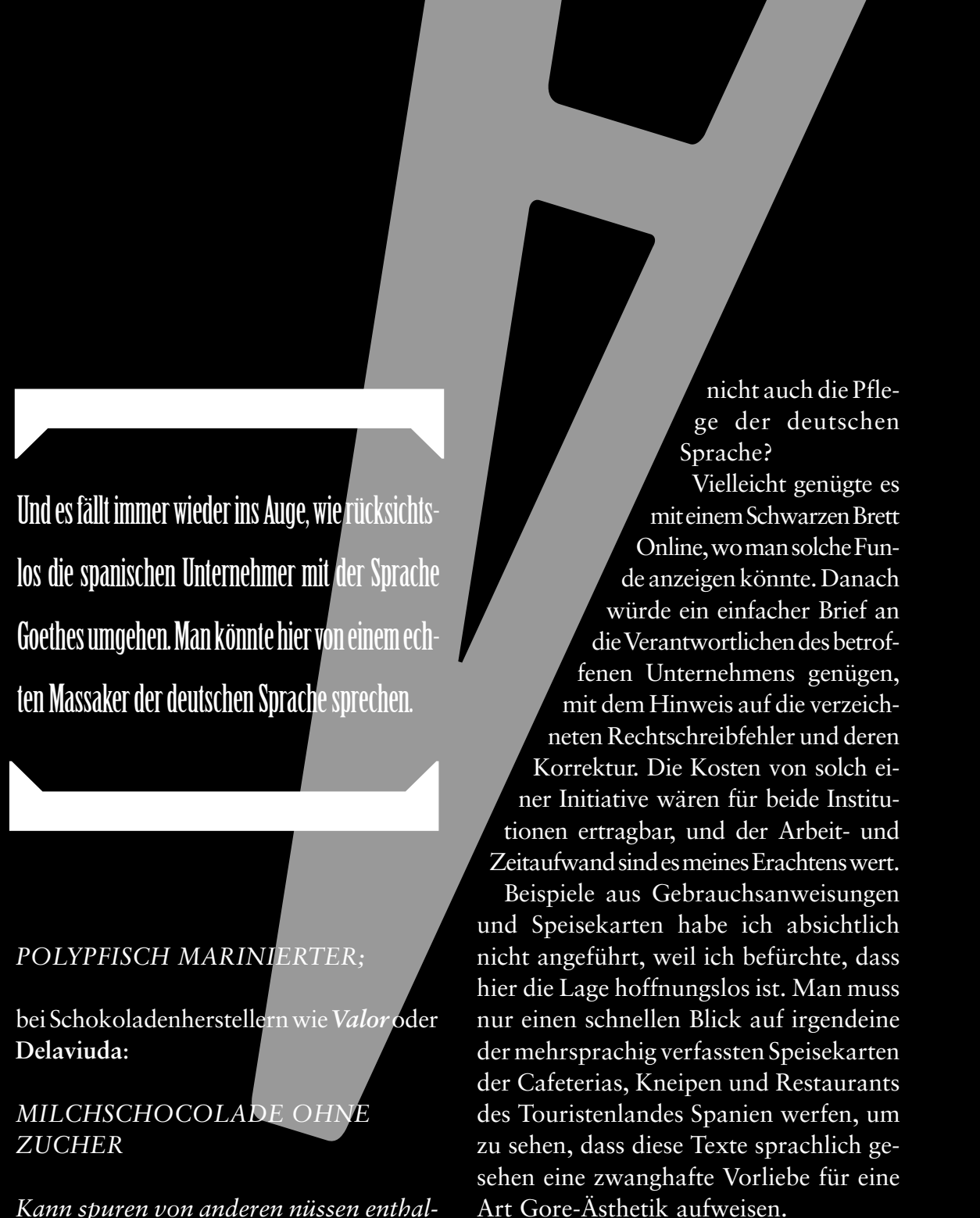
ten;

und sogar im Reiseführer von El Pais Aguilar stöbt man im Anhang auf Attentate wie:

Soy español - Ich bin Spanischer

El aeropuerto? - der Flugplatz?

El consulado español? - das Spanischer Konsulat?

Entradas: Hauptspeisen

Langostino: Languste

Rodaballo: Rotbarsch

Empanada de carne: Frikadelle

Ich bin der Meinung, dass das GoetheInstitut, vielleicht in enger Zusammenarbeit mit der FAGE, etwas dagegen machen könnte/müsste. Gehört zu den Aufgaben des Goethe-Instituts schlieblich
Das Centro de Linguas Modernas der Universität Santiago de Compostela überreichte vor einigen Jahren der Asociación de Hosteleros de Santiago ein Glossar mit rund 1500 Eintragungen auf Französisch, Englisch und Deutsch, damit dieser Verband vorerst seinen Mitgliedern, aber nebenbei auch den Sprachen Molières, Shakespeares und Goethes einen guten Dienst leisten konnte, aber die Lage hat sich kaum verbessert: In den Kneipen der Rúa do Franco in Santiago de Compostela ist das Grinsen der deutschen Pilger und Touristen beim Bestellen der Gerichte so fest in das Bild der Stadt verwurzelt, wie die Fassade der Kathedrale oder das Schwingen des Botafumeiros.

Kann dagegen wirklich nichts getan werden? 